\title{
THE FRIEDRICHS-WIRTINGER TYPE INEQUALITY AND ITS APPLICATION TO THE TRANSMISSION PROBLEM IN A CONICAL DOMAIN
}

\author{
MIKHAIL BORSUK
}

Abstract. We formulate the new Friedrichs-Wirtinger type inequality with the sharp constant and apply it to the investigation of the behavior of weak solutions to the transmission problem for linear elliptic divergence second order equations in a neighborhood of the boundary conical point. We establish the precise rate of decreasing of the solution.

Mathematics subject classification (2010): 35J25, 35J60, 35J85, 35B65.

Keywords and phrases: Sharp integro-differential inequalities, elliptic equations, the transmission problem, conical points.

\section{REFERENCES}

[1] M.V. BoRSUK, A priori estimates and solvability of second order quasilinear elliptic equations in a composite domain with nonlinear boundary conditions and conjunction condition, Proc. Steklov Inst. of Math., 103 (1970), 13-51.

[2] M. Borsuk, V. Kondratiev, Elliptic Boundary Value Problems of Second Order in Piecewise Smooth Domains, North-Holland Mathematical Library, 69, ELSEVIER (2006), 531 pp.

[3] Ya-Zhe Chen, LAn-Cheng Wu, Second order elliptic equations and elliptic systems, Translated of Mathematical Monographs, 174, (1998). AMS, Providence, Rhode Island, 246 pp.

[4] W. Chikouche, D. Mercier AND S. NicAise, Regularity of the solution of some unilateral boundary value problems in polygonal and polyhedral domains, Communications in partial differential equations, 29, 1\&2 (2004), 43-70.

[5] D. Gilbarg And N.S. Trudinger, Elliptic Partial Differential Equations of Second Order, Springer-Verlag, Berlin/Heidelberg/New York, 1977. Revised Third Printing, 1998.

[6] V.A. IL'IN, On the solvability of the Dirichlet and Neumann problems for linear elliptic operator with discontinuous coefficients, Doklady AN USSR., 137, 1 (1961), 28-30.

[7] D. KaPANADZE, B.-W. Schulze, Boundary-contact problems for domains with conical singularities, Journal of Differential Equations, 217, 2 (2005), 456-500.

[8] D. KAPAnADZE, B.-W. Schulze, Boundary-contact problems for domains with edge singularities, Journal of Differential Equations, 234 (2007), 26-53.

[9] O.A. LADYZHENSKAYA, N.N. URAL'TSEVA, Linear and Quasilinear Elliptic Equations, Academic Press, New York, 1968.

[10] S. Nicaise, Polygonal Interface Problems, Peter Lang (1993), 250 pp. (Methoden und Verfahren der mathematischen Physik; Bd. 39).

[11] S. NiCAise, A.-M. Sändig, General interface problems I, II, Math. Meth. Appl. Sci, 17, 6 (1994), 395-450.

[12] Z.G. SHEFTEL, Estimates in $L_{p}$ of solutions of elliptic equations with discontinuous coefficients and satisfying general boundary conditions and conjugacy conditions, Soviet Math. Dokl., 4 (1963), 321324. 